\title{
Layered Double Hydroxide Modified with Deoxycholic and Hyaluronic Acids for Efficient Oral Insulin Absorption
}

\author{
Xia Huang ${ }^{1} *$ \\ Shangcong Han ${ }^{1, *}$ \\ Zuxian Chen' \\ Lei Zhao $\mathbb{D}^{2}$ \\ Changduo Wang' \\ Qingyang Guo ${ }^{3}$ \\ Yanfeng $\mathrm{Li}^{\prime}$ \\ Yong Sun (1D'
}

'Department of Pharmaceutics, School of Pharmacy, Qingdao University, Qingdao, People's Republic of China; ${ }^{2}$ Lunan Better Pharmaceutical Co., Ltd, Linyi, People's Republic of China; ${ }^{3}$ College of Fisheries, Henan Normal University, Xinxiang, People's Republic of China

*These authors contributed equally to this work
Correspondence: Yong Sun

Email sunyong@qdu.edu.cn
Introduction: This study aimed to construct a layered double hydroxide (LDH) nanoparticle delivery system that was modified by deoxycholic acid (DCA) and hyaluronic acid (HA) to increase the bioavailability of oral insulin.

Methods: LDH-DCA-HA was synthesized by the hybridization of DCA and HA with LDH. Subsequently, insulin was loaded onto LDH-DCA-HA, resulting in the formation of INS@LDH-DCA-HA. The in vivo and in vitro mechanisms of insulin release, as well as the efficiency of insulin absorption, were analyzed before and after DCA-HA modification. Results: MTT assay showed that there was satisfactory biocompatibility between LDH-DCA-HA and Caco- 2 cells at a concentration below $1000 \mu \mathrm{g} / \mathrm{mL}$. Flow cytometry analysis revealed that Caco-2 cells absorbed INS@LDH-DCA-HA more readily than insulin. Measurement of transepithelial electrical resistance indicated that INS@LDH-DCA-HA induced the reversible opening of tight cell junctions, thereby facilitating its absorption. This was confirmed via laser confocal microscopy analysis, revealing that a large amount of zonula occludens- 1 tight junction (TJ) protein was utilized for the paracellular pathway of nanoparticles. We also measured the blood glucose levels of type I diabetic mice and found that oral INS@LDH-DCA-HA exerted a steady hypoglycemic effect lasting $12 \mathrm{~h}$, with a small range of postprandial blood glucose fluctuation. Immunofluorescence analysis showed that the strong penetration ability of INS@LDH-DCA-HA allowed insulin to enter epithelial cells more readily than free insulin. Finally, immunohistochemical analysis of anti-SLC10A1 protein confirmed that the cholic acid transporter receptor protein played a key role in the functioning of INS@LDH-DCA-HA.

Conclusion: LDH nanoparticles modified by DCA and HA improved the absorption efficiency of insulin by opening the TJs of cells and interacting with the cholic acid transporter receptor protein.

Keywords: nanoparticle delivery system, insulin bioavailability, hypoglycemic effect, tight junctions

\section{Introduction}

Insulin use enables diabetics to adequately control their blood sugar levels. However, when insulin resistance develops, the gradual increase in insulin that is necessary results in increasingly harmful side effects. ${ }^{1}$ Therefore, increasing the efficiency of insulin utilization is essential for the effective management of diabetes.

Inorganic nanomaterials are widely used in the treatment of a variety of diseases, with reported anti-cancer, anti-inflammatory, and anti-diabetic activity. ${ }^{2}$ Specifically, a new layered double hydroxide $(\mathrm{LDH})$ can be modified to extend the performance of nanoparticles. ${ }^{3}$ Studies have shown that loading a drug into an LDH can decelerate 
release of the drug, thereby reducing the administration frequency and enhancing the efficacy of treatments against inflammation, cancer, and cardiovascular disease. ${ }^{4}$

Deoxycholic acid (DCA) is a type of secondary bile acid that possesses strong surface activity and the ability to destroy and dissolve cell membranes. By increasing the degree of substitution of DCA, the encapsulation efficiency (EE) of a drug can be enhanced, along with achieving a slower release rate. ${ }^{5}$ Therefore, DCA is an excellent choice for the modification of nanoparticles.

Hyaluronic acid (HA) is a naturally occurring polymer ${ }^{6}$ that is widely used in drug and gene delivery systems ${ }^{6,7}$ due to its level of biocompatibility and ease of modification of its chemical structure. Previous studies have shown that insulinloaded HA nanoparticles enhance the transport of insulin in the duodenum and ileum ${ }^{8}$ while also facilitating the smooth passage of nanoparticles through the intestinal mucus layer. ${ }^{9}$ Moreover, other studies have suggested that HA may be an option for promoting interaction between the intestinal wall and insulin nanocarriers, as it presents the advantage of improved mucus penetration. ${ }^{10}$ For example, DCA-HA, developed by Liu et al, reverses multidrug resistance by enhancing the delivery of paclitaxel. ${ }^{11}$

In this study, synthesized LDH was first modified with DCA and HA and then loaded with insulin to prepare INS@LDH-DCA-HA. The aim was to explore the in vivo transport mechanism of oral insulin and release of the drug after absorption from the perspective of inorganic nanomaterials. We hope to provide a theoretical basis for the design and construction of hepato-targeted bionic nanocarriers with high transmembrane transport efficiency.

\section{Materials and Methods \\ Preparation of LDH-DCA-HA and INS@LDH-DCA-HA}

A $60-\mathrm{mL}$ volume of methanol containing $0.48 \mathrm{~g} \mathrm{NaOH}$ was mixed with $20 \mathrm{~mL}$ methanol, in which $6 \mathrm{mM} \mathrm{Mg}$
$\left(\mathrm{NO}_{3}\right)_{2} \cdot 6 \mathrm{H}_{2} \mathrm{O}$ had been dissolved along with $2 \mathrm{mM} \mathrm{Al}$ $\left(\mathrm{NO}_{3}\right)_{3} \cdot 9 \mathrm{H}_{2} \mathrm{O}$. The suspension was vigorously stirred for 10 min under a $\mathrm{N}_{2}$ atmosphere, after which the solid precipitate was collected by centrifugation and washed thoroughly with $40 \mathrm{~mL}$ anhydrous ethanol several times. LDH freeze-dried powder was obtained after subsequent cooling and drying. A 100-mg sample of LDH freeze-dried powder was resuspended in $10 \mathrm{~mL}$ anhydrous ethanol, and then, $200 \mu \mathrm{L}$ of (3-aminopropyl) triethoxysilane (APTES) was added. The mixture was magnetically stirred at $25^{\circ} \mathrm{C}$ for $24 \mathrm{~h}$. After cooling and drying, $10 \mathrm{~mL}$ deionized water was added for resuspension, followed by $15 \mathrm{mg} \mathrm{HA}, 5 \mathrm{mg}$ DCA, as well as catalytic amount of N-hydroxysuccinimide (NHS) and 1-(3-dimethylaminopropyl)-3-ethylcarbodiimide (EDC) hydrochloride (Scheme 1).

Magnetic stirring was performed at $25^{\circ} \mathrm{C}$ for $8 \mathrm{~h}$, whereafter the product was dialyzed in deionized water for $24 \mathrm{~h}$ and then lyophilized to obtain the final product, namely LDH-DCA-HA. In subsequent experiments, $10 \mathrm{mg}$ LDH-DCA-HA freeze-dried powder was dissolved in $10 \mathrm{~mL}$ deionized water to obtain an LDH-DCA-HA solution. Next, $10 \mathrm{mg}$ insulin was diluted with $10 \mathrm{~mL} \mathrm{HCl}$ solution $\left(0.01 \mathrm{~mol} \cdot \mathrm{L}^{-1}\right)$, and then, the $\mathrm{pH}$ was adjusted to 7.0 by $1 \mathrm{~mol} \cdot \mathrm{L}^{-1} \mathrm{NaOH}$. The LDH-DCA-HA and insulin solutions were combined and ultrasonically heated for 30 min at $60^{\circ} \mathrm{C}$ to obtain INS@LDH-DCA-HA nanoparticles. $\mathrm{NaOH} \quad(\mathrm{CP}), \quad \mathrm{Mg}\left(\mathrm{NO}_{3}\right)_{2} \cdot 6 \mathrm{H}_{2} \mathrm{O} \quad(\mathrm{CP}), \quad \mathrm{Al}$ $\left(\mathrm{NO}_{3}\right)_{3} \cdot 9 \mathrm{H}_{2} \mathrm{O}(\mathrm{CP})$, APTES (AR), HA (AR), DCA (AR), NHS (AR), and EDC (AR) were all purchased from Sigma-Aldrich (St. Louis, MO, USA).

\section{Analysis of Particle Size, Polydispersity Index, Zeta Potential, and Morphology of Nanoparticles}

The particle size, polydispersity index (PDI) coefficient, and zeta potential of LDH, LDH-DCA-HA, and INS@LDH-DCA-HA nanoparticles were determined

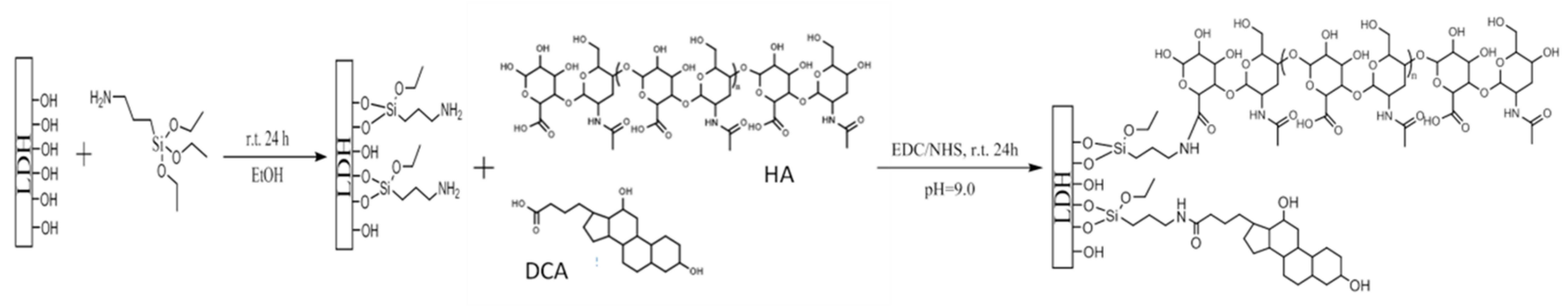

Scheme I Synthesis route of LDH-DCA-HA. 
using a Zetasizer Nano (Malvern Panalytical, Ltd., Malvern, Birmingham, UK). The morphology of LDH and LDH-DCA-HA was analyzed via transmission electron microscopy (TEM; Hitachi, Tokyo, Japan).

\section{Surface Element Analysis}

LDH and LDH-DCA-HA were examined by X-ray photoelectron spectroscopy (XPS) using an X-ray photoelectron spectrometer (Thermo Fisher Scientific, Waltham, MA, USA) to determine the types and proportions of surface elements for elemental analysis. The mass change, thermogravimetric analysis (TGA), and derivative thermogravimetric curves of the samples were determined via simultaneous thermal analysis (STA), using an STA 449 F3 Jupiter ${ }^{\circledR}$ thermal analysis instrument (Netzsch, Selb, Germany.) The experimental parameters included a heating rate of $10^{\circ} \mathrm{C} / \mathrm{min}$, temperature range of $25-500^{\circ} \mathrm{C}$, and a flow rate of high purity nitrogen equaling $20 \mathrm{~mL} / \mathrm{min}$.

\section{Thermogravimetric Analysis}

The mass change, thermogravimetric analysis (TGA), and derivative thermogravimetric curves of the samples were determined via simultaneous thermal analysis (STA), using an STA 449 F3 Jupiter ${ }^{\circledR}$ thermal analysis instrument (Netzsch, Selb, Germany.) The experimental parameters included a heating rate of $10^{\circ} \mathrm{C} / \mathrm{min}$, temperature range of $25-500^{\circ} \mathrm{C}$, and a flow rate of high-purity nitrogen equaling $20 \mathrm{~mL} / \mathrm{min}$.

\section{Brunauer-Emmett-Teller Analysis}

The Brunauer-Emmett-Teller (BET) model was applied to determine the specific surface area parameters of LDHDCA-HA and INS@LDH-DCA-HA nanoparticles at $30^{\circ} \mathrm{C}$, following vacuum pretreatment for $6 \mathrm{~h}$, and using $-196^{\circ} \mathrm{C}$ liquid nitrogen as the adsorbent.

\section{Phase Analysis of X-Ray Diffraction}

The loading mode of LDH-DCA-HA was analyzed by X-ray diffraction (XRD) using a Benchtop XRD Analyzer (Olympus, Tokyo, Japan) with $\mathrm{Cu}-\mathrm{K} \alpha$ as the $\mathrm{X}$-ray emission source, at $40 \mathrm{kV}$ voltage, $60 \mathrm{~mA}$ current, and a diffraction range of $5-50^{\circ}$. The Shelley equation $(2 \operatorname{dsin} \theta=n \lambda)$ was used to calculate lamellar spacing, and the full width at half maximum of the (003) crystal plane diffraction peak was used to calculate lamellar thickness. Moreover, the strength and sharpness of the diffraction peaks were used to measure the crystallinity of the crystal structure.

\section{Encapsulation Rate and Drug Loading Analysis}

Different insulin concentrations- $-0.25,0.50,0.75$, and $1.00 \mathrm{mg} \cdot \mathrm{mL}^{-1}$ — were loaded into LDH-DCA-HA and centrifuged at $13,000 \mathrm{rpm}$ for $30 \mathrm{~min}$, at $4^{\circ} \mathrm{C}$. The amount of insulin in the supernatant was analyzed using high performance liquid chromatography (HPLC), whereafter it was loaded into INS@LDH-DCA-HA. The EE was calculated using the following equations: encapsulation rate $\%=$ (total insulin - supernatant insulin amount)/total insulin amount $\times 100$, and drug loading amount $(\%)=$ (total insulin - supernatant insulin amount)/nanometer mile mass $\times 100$. HPLC analysis was performed at $214 \mathrm{~nm}$ on a ZORBAX ${ }^{\circledR}$ SB-C18 column (Agilent, Palo Alto, CA, USA) $-150 \mathrm{~mm} \times 4.6 \mathrm{~mm}, 5 \mu \mathrm{m}$-with a mobile phase composed of $0.1 \mathrm{~mol} / \mathrm{L}$ sodium dihydrogen phosphate at $\mathrm{pH} 3.0$, and acetonitrile $(72: 28, \mathrm{v} / \mathrm{v})$.

\section{MTT Assay Analysis of the Effect of INS@LDH-DCA-HA on Caco-2 Cell}

\section{Survival Rate}

Caco-2 human epithelial colorectal adenocarcinoma cells were purchased from the American Type Culture Collection (ATCC, Manassas, VA, USA) and maintained in Dulbecco's modified Eagle's medium (DMEM) supplemented with Gibco $^{\circledR} 10 \%$ fetal bovine serum (FBS; Thermo Fisher Scientific). LDH-DCA-HA and INS@LDH-DCA-HA were each incubated with Caco-2 cells for $24 \mathrm{~h}$. Thereafter, $10 \mu \mathrm{L}$ MTT reagent (Beyotime, Shanghai, China) was added to the medium, according to the manufacturer's instructions, and the optical density (OD) was measured using an enzyme-labeled instrument (TECAN, Geneva, Switzerland).

\section{Flow Cytometry Analysis}

Caco- 2 cells were seeded at $2 \times 10^{5}$ cells per well in 6-well plates and incubated at $37^{\circ} \mathrm{C}$ for $24 \mathrm{~h}$. The cells were then separately incubated for $4 \mathrm{~h}$ with fluorescein isothiocyanate (FITC)-insulin, FITC-insulin@LDH, or FITCinsulin@LDH-DCA-HA. Then, we removed the culture medium, and the cells were washed 3 times with cold phosphate-buffered saline (PBS). Next, cells were digested using $0.25 \%$ trypsin and were then centrifuged, collected, dispersed, and finally renewed in a solution of $0.50 \mathrm{~mL}$ cold PBS for detection by flow cytometry (BD, ACCURI C6). 


\section{Transmembrane Resistance Analysis}

Caco-2 cells $\left(2 \times 10^{5}\right)$ were seeded into the upper compartment of a serum-free Transwell culture system, while $10 \%$ FBS medium was added to the lower chamber, and the system was cultured for 48-96 h until the transepithelial electrical resistance (TEER) met the requirements for the experiment. ${ }^{12}$ The chamber was then washed twice with PBS and placed into a new 24-well plate. Hanks Balanced Salt Solution buffer was added to the lower layer, and either insulin solution or INS@LDH-DCA-HA was added to the upper layer. The chamber was incubated at $37^{\circ} \mathrm{C}$ in a $\mathrm{CO}_{2}$ environment for $2 \mathrm{~h}$, whereafter TEER was measured to analyze the tightness of Caco- 2 cell barriers. The apparent permeability coefficient (Papp) was calculated as follows: Papp $=$ drug permeability $/($ membrane area $\times$ upper chamber drug concentration $\times$ total experiment time). The required criteria for the experiment were: 500 $\Omega \cdot \mathrm{cm}^{2}<$ TEER $<1500 \Omega \cdot \mathrm{cm}^{2}$, Papp $<1 \times 10^{-6} \mathrm{~cm} / \mathrm{s}$.

\section{Confocal Laser Scanning Microscopy}

Caco-2 cells were co-incubated with INS@LDH-DCA-HA for $2 \mathrm{~h}$ and then incubated with $4 \%$ paraformaldehyde at $25^{\circ} \mathrm{C}$ for $15 \mathrm{~min}$. After rinsing twice with PBS, the preparation was combined with anti-ZO-1 tight junction (TJ) protein antibody (1:100, ab221547; Abcam, Cambridge, UK), and incubated in darkness at $25^{\circ} \mathrm{C}$ for $30 \mathrm{~min}$. Thereafter, donkey anti-rabbit IgG secondary antibody conjugated with Alexa Fluor $^{\circledR} 647$ (1:100, ab150075; Abcam) was added, and the preparation was incubated for a further $30 \mathrm{~min}$. After rinsing twice more with PBS, a Leica TCS SP8 MP confocal microscope (Leica Microsystems, Mannheim, Germany) was used to conduct confocal laser scanning microscopy (CLSM) at an excitation wavelength of $647 \mathrm{~nm}$.

\section{Establishment of a Mouse Model of Type I Diabetes}

All animal experiments were carried out in compliance with the Animal Management Rules of the Ministry of Health of the People's Republic of China (document no. 55, 2001) and were approved by the Committee on Medical Ethics of the Qingdao University Affiliated Hospital (Qingdao, China). Male BALB/c mice were purchased from Qingdao Daren Fortune Animal Technology Co., Ltd. (Qingdao, Shandong, China), and subjected to routine inspection and quarantine in a barrier environment for $7 \mathrm{~d}$. The mice were fed a standard chow diet and water ad libitum and were subjected to a 12-h alternating light/ dark cycle in an environment with approximately $60-65 \%$ humidity. To establish the type I diabetes model, mice were disinfected with $75 \%$ alcohol and injected once daily with $60 \mathrm{mg} / \mathrm{kg}$ streptozotocin (Sigma-Aldrich), for 10 consecutive days. Modeling was considered successful once blood glucose levels were higher than $11.1 \mathrm{mM} / \mathrm{L}$.

\section{Hypoglycemic Effect of INS@LDH-DCA- HA}

Diabetic mice were randomly divided into oral INS@LDHDCA-HA ( $\mathrm{n}=6 ; 60 \mathrm{IU} / \mathrm{kg})$, subcutaneous insulin injection (positive control; $\mathrm{n}=6 ; 5 \mathrm{IU} / \mathrm{kg}$ ), oral free insulin (negative control (NC)); $\mathrm{n}=6 ; 60 \mathrm{IU} / \mathrm{kg}$ ), or oral LDH (blank control; $\mathrm{n}=6 ; 60 \mathrm{IU} / \mathrm{kg}$ ) groups. Blood was collected from the tail veins of the mice before administration, and again at 1,2, 4, $6,8,10$, and $12 \mathrm{~h}$ after administration. Blood glucose levels were measured using a GA-3 glucose meter (Sinocare Inc., Changsha, Hunan, China).

\section{Intestinal Absorption in vivo}

Mice were anesthetized with $70 \mathrm{mg} / \mathrm{kg}$ sodium pentobarbital, whereafter the small intestine was exposed by laparotomy, and a $2-\mathrm{cm}$ intestinal loop ligated at both ends. A $500-\mu \mathrm{L}$ volume of either FITC-labeled INS@LDHDCA-HA or FITC-insulin was injected into the ligated section of the small intestine, and the abdominal cavity was sutured. The treated intestine was removed $1 \mathrm{~h}$ later (following euthanasia of the mice), rinsed with PBS, and fixed with $4 \%$ paraformaldehyde. The intestinal epithelium was treated with anti-SLC10A1 protein antibody and analyzed via immunohistochemistry (IHC). A receptorblocked experiment was carried out by oral administration with deoxycholic acid 2 hours before the mice were killed.

\section{Statistical Analysis}

The data were analyzed using descriptive statistics, singlefactor analysis of variance (ANOVA), and are presented as the mean \pm standard deviation (SD), averaged across three to five independent measurements. Comparisons among treatment groups were performed by independent sample Student's $t$ tests. Differences were considered as significant, and the null hypothesis of no difference among treatment groups was rejected for $* \mathrm{P}<0.05, * * \mathrm{P}<0.01$, and $* * * \mathrm{P}<0.001$. 


\section{Results}

\section{Particle Size and Morphology of Nanoparticles}

TEM analysis showed that LDH presented with a hexagonal, lamellar structure (Figure 1E). However, following modification with DCA and HA, LDH presented with a smooth, spherical shape (Figure 1F). Moreover, the particle size of LDH-DCA-HA increased from 158.7 to $285.9 \mathrm{~nm}$, and the surface potential of LDH-DCA-HA changed from $+20.4 \mathrm{mV}$ to $-17.2 \mathrm{mV}$, proving that HA had been successfully coated in an outer layer of LDH nanoparticles. Furthermore, the PDI values of LDH and LDH-DCA-HA were 0.196 and 0.210, respectively, showing no significant change (Table 1). The diameter of INS@LDH-DCA-HA increased, and its zeta potential decreased after loading insulin. These results indicated that LDH-DCA-HA was successfully loaded with insulin. Furthermore, there was no significant difference in the PDI, indicating that the nanocarriers possessed homogeneous stability. ${ }^{13}$

\section{X-Ray Photoelectron Spectroscopy Analysis}

Comparative XPS analysis results for LDH and LDH-DCA$\mathrm{HA}$ are shown in Figure $1 \mathrm{~A}$ and B. An obvious Si peak appeared for LDH-DCA-HA, which was not observed in LDH, proving that APTES had successfully conjugated on the surface of LDH (Figure 1C). The evident N-peak shift of LDH-DCA-HA was due to the obvious difference in XPS electron escape energy between ammonia-N of HA and nitrate-N of LDH (Figure 1D). Therefore, we determined that the surface of the LDH sheets had been successfully modified by a silane coupling agent and bonded with HADCA to form an organic coating.

\section{Thermogravimetric Analysis}

The first stage of thermogravimetric analysis (TGA) usually involves loss of mass due to water evaporation, whereas the second stage entails mass loss due to the gasification of organic matter. Our results showed that the mass of LDH was reduced by $5.79 \%$ and $12.13 \%$ during the first and second stages, respectively. (Figure 2). The mass of LDH-DCA-HA decreased by $22.32 \%$ in the second stage, which was $10.19 \%$ lower than the second stage mass loss of LDH. Therefore, the mass ratio of LDH to DCA-HA in LDH-DCA-HA was $89.91 \%$ to $10.19 \%$, respectively.

\section{Brunauer-Emmett-Teller Analysis}

The BET adsorption experiment showed that the lamellar structure of the multilayer nanoparticles was complete, and that insulin was successfully intercalated into LDH-DCAHA because the BET surface area, pore volume, and pore size were clearly decreased (shown in Table 2).

\section{X-Ray Diffraction Analysis}

Based on the diffraction peaks of the substrate at crystal planes (003), (006), and (009), it was determined that the $\mathrm{LDH}$ prepared in this study possessed a hydrotalcite-like lamellar structure with a calculated LDH lamellar spacing of approximately $0.785 \mathrm{~nm}$, and thickness of roughly 20 nm. Peaks (003) and (006) became blunt, and the two small peaks to the left of (006) became more obvious (Figure 3). These results confirmed that insulin was successfully loaded into the LDH layers by means of intercalation.

\section{Determination of Encapsulation Efficiency and Drug Loading of Insulin}

The HPLC results showed that there was a decreasing trend for the encapsulation rate and drug loading capacity (LC) of INS@LDH-DCA-HA with increasing insulin concentration. At an insulin concentration of $0.25 \mathrm{mg} \bullet \mathrm{mL}^{-1}$, the $\mathrm{EE}$ and LC of drug-loaded nanoparticles reached their maximums of $66 \%$ and $33 \%$, respectively (Figure 4 ).

\section{Cytotoxicity of Nanocarriers}

The MTT assay results showed that cell viability gradually decreased with an increase in the concentration of LDHDCA-HA or INS@LDH-DCA-HA, but at LDH-DCA-HA or INS@LDH-DCA-HA concentrations $\leq 1000 \mu \mathrm{g} / \mathrm{mL}$, cell viability exceeded $60 \%$, which indicated that there was satisfactory biocompatibility with Caco-2 cells (Figure 5).

\section{Cell Uptake Analysis of INS@LDH and INS@LDH-DCA-HA}

Flow cytometry analysis showed that the fluorescence intensity of INS@LDH-DCA-HA was higher than that of the control group, INS@LDH group, and INS group. These results suggested that the addition of DCA and HA strengthened the binding between cells and LDH, and it was easier for the nanoparticles to be uptaken by cells after being loaded with insulin (Figure 6). 

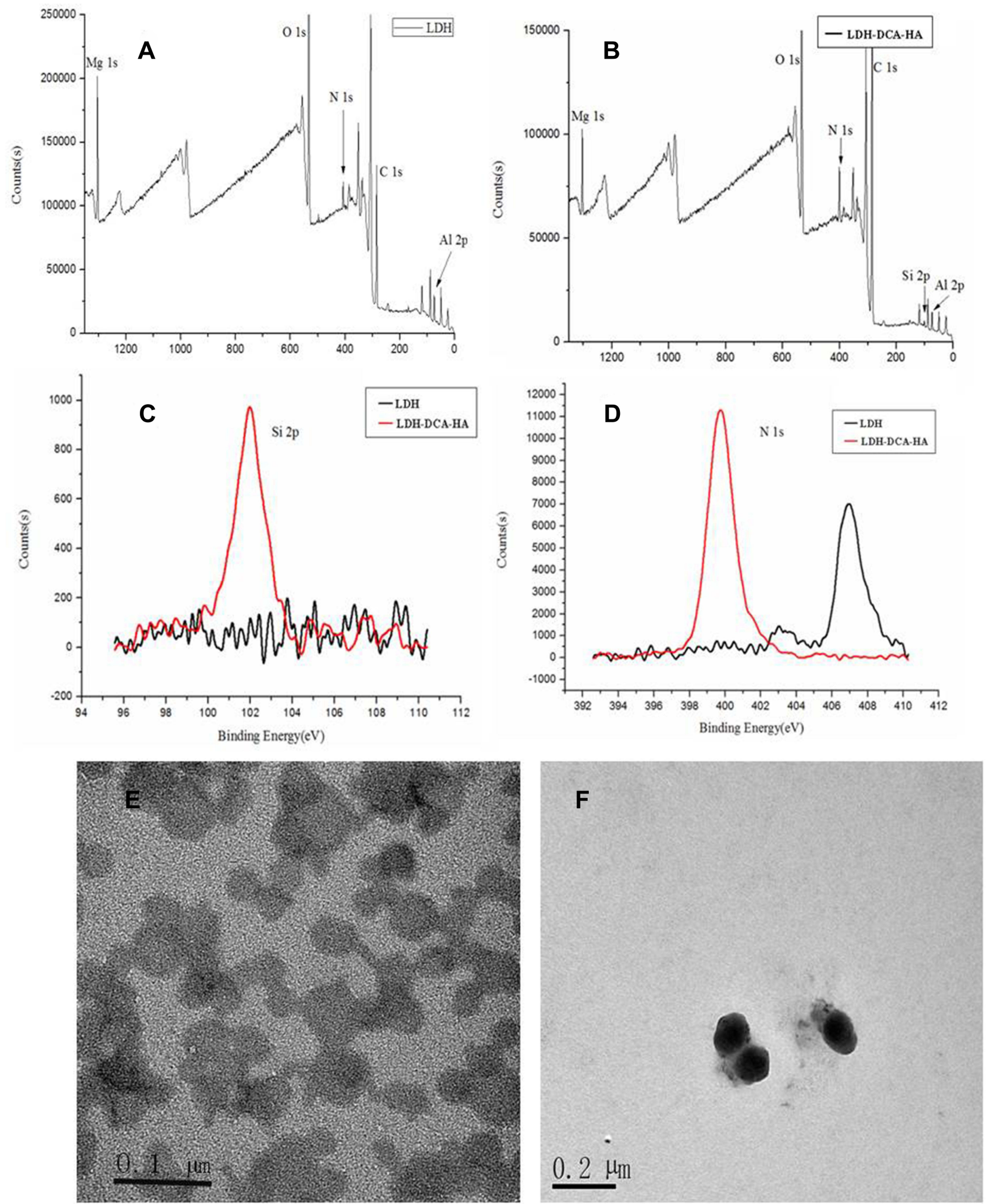

Figure I X-ray photoelectron spectroscopy analysis of LDH and LDH-DCA-HA. (A-D); morphology of LDH (E) and LDH-DCA-HA (F) by TEM. 
Table I Particle Size, Polydispersity Index, and Zeta Potential of LDH, LDH-DCA-HA, and INS@LDH-DCA-HA

\begin{tabular}{|l|l|l|l|}
\hline Classification & LDH & $\begin{array}{l}\text { LDH-DCA- } \\
\text { HA }\end{array}$ & $\begin{array}{l}\text { INS@LDH-DCA- } \\
\text { HA }\end{array}$ \\
\hline Particle size $/ \mathrm{nm}$ & $158.7 \pm 1.16$ & $285.9 \pm 2.21$ & $303.2 \pm 3.15$ \\
Zeta potential/mV & $+20.4 \pm 0.42$ & $-17.2 \pm 0.44$ & $-20.8 \pm 0.53$ \\
PDI & 0.196 & 0.210 & 0.200 \\
\hline
\end{tabular}

\section{Transmembrane Transport Capacity Analysis}

TEER analysis showed a decrease in the TEER value of Caco-2 when exposed to INS@LDH-DCA-HA, compared with that of the free insulin solution. After removal of the

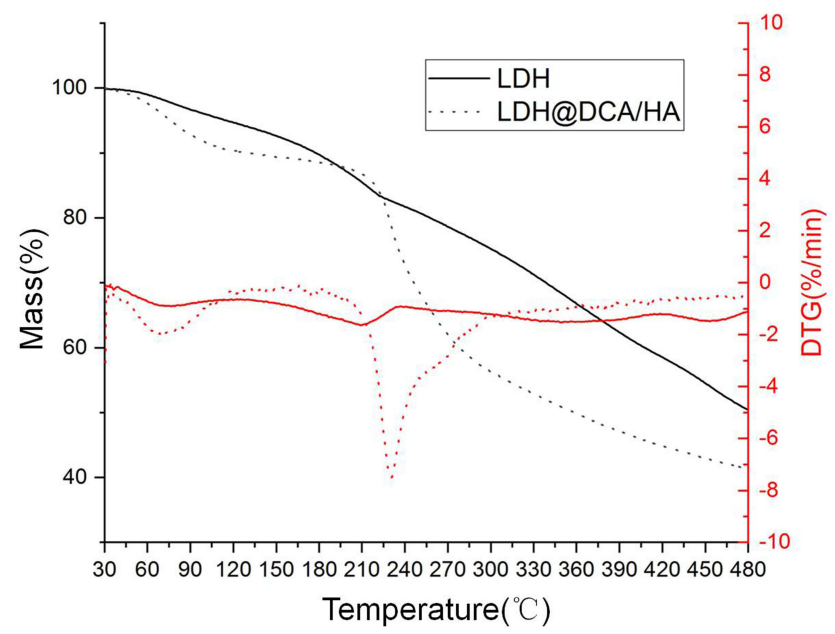

Figure $\mathbf{2}$ Thermogravimetric analysis of LDH and LDH-DCA-HA.
Table 2 BET Surface Area, Pore Volume and Pore Size of LDHDCA-HA and INS@LDH-DCA-HA

\begin{tabular}{|l|l|l|l|}
\hline & $\begin{array}{l}\text { BET Surface } \\
\text { Area }\left(\mathbf{m}^{2} / \mathbf{g}\right)\end{array}$ & $\begin{array}{l}\text { Pore Volume } \\
\left(\mathbf{c m}^{3} / \mathbf{g}\right)\end{array}$ & $\begin{array}{l}\text { Pore } \\
\text { Size } \\
(\mathbf{n m})\end{array}$ \\
\hline LDH-DCA-HA & 52.5688 & 0.107 & 0.74 \\
INS@LDH-DCA-HA. & 20.3788 & 0.021 & 0.42 \\
\hline
\end{tabular}

insulin nanoparticles or solution, the TEER value of the INS@LDH-DCA-HA group gradually recovered (Figure 7A), suggesting that INS@LDH-DCA-HA was able to reversibly open the TJs of cells. Additionally, the Papp value of INS@LDH-DCA-HA $\left((10.86 \pm 0.54) \times 10^{-7}\right)$ was significantly higher than that of the insulin group ((4.71 $\pm 0.46) \times 10^{-7}$ ) (Figure 7B), and the Papp of both groups was $<1 \times 10^{-6} \mathrm{~cm} / \mathrm{s}$, which met the standard. ${ }^{14}$ It may be the case that HA and DCA can enhance the transmembrane transport of insulin to a large extent. Moreover, INS@LDH-DCA-HA-mediated cell bypass transport also had a positive effect on the transmembrane transport of insulin.

\section{Alteration of Caco-2 TJs by INS@LDH-DCA-HA}

Immunofluorescence CLSM showed that the TJ protein zonula occludens-1 (ZO-1) was distributed in a continuous ring around the cell. Furthermore, the expression of ZO-1 significantly decreased after a $2 \mathrm{~h}$ incubation with INS@LDH-DCA-HA, suggesting that ZO-1 could be

\section{(003)}

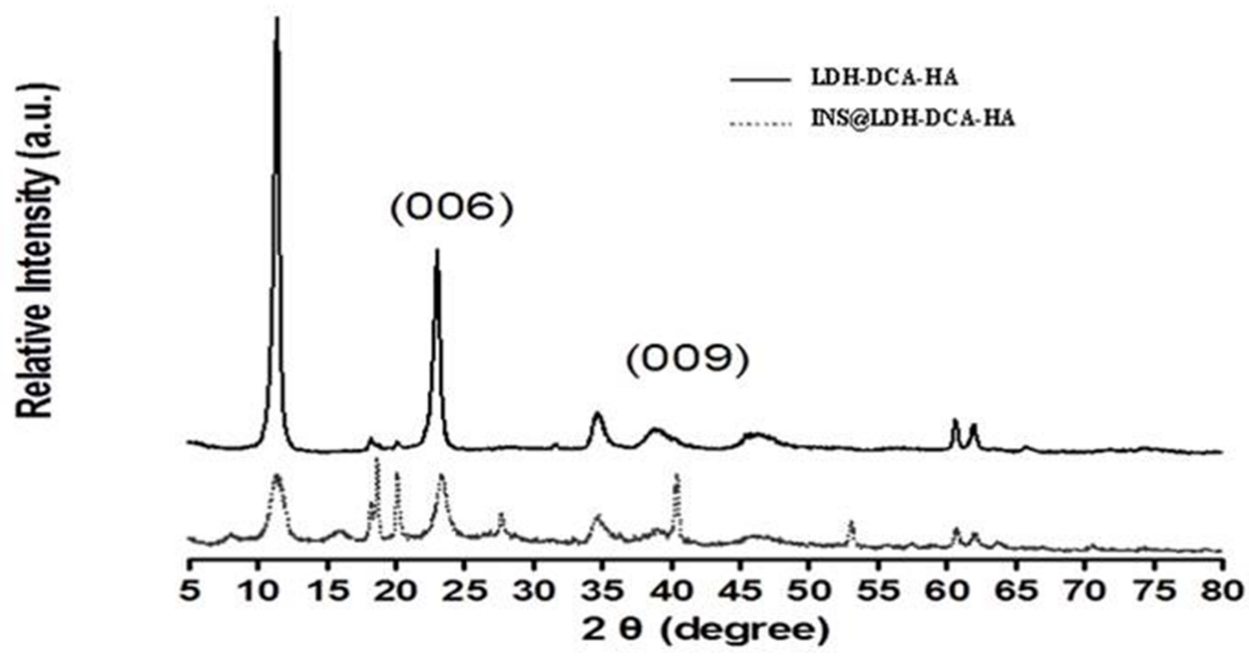

Figure 3 X-ray diffraction analysis of insulin intercalated into LDH-DCA-HA. 


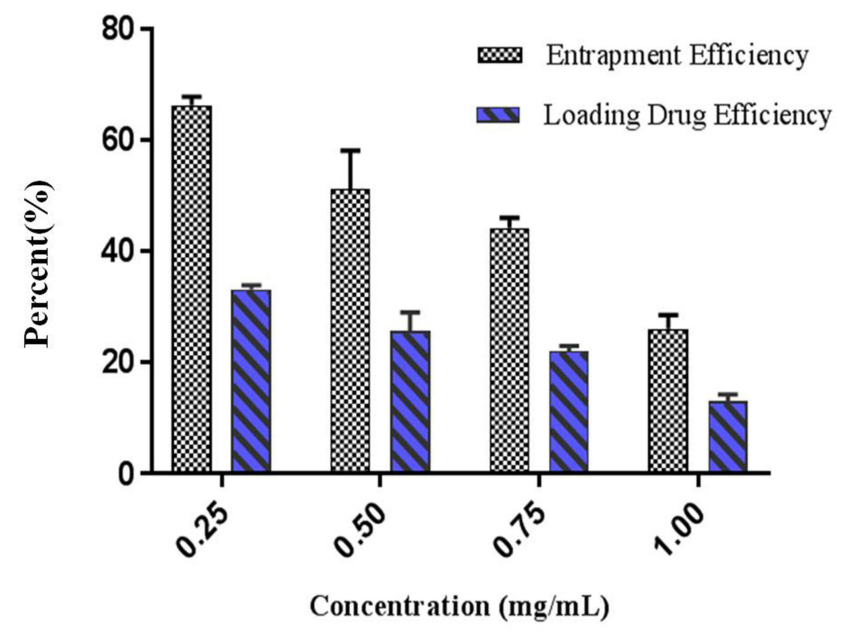

Figure 4 Encapsulation efficiency and drug loading efficiency of insulin.

Caco-2 cell line

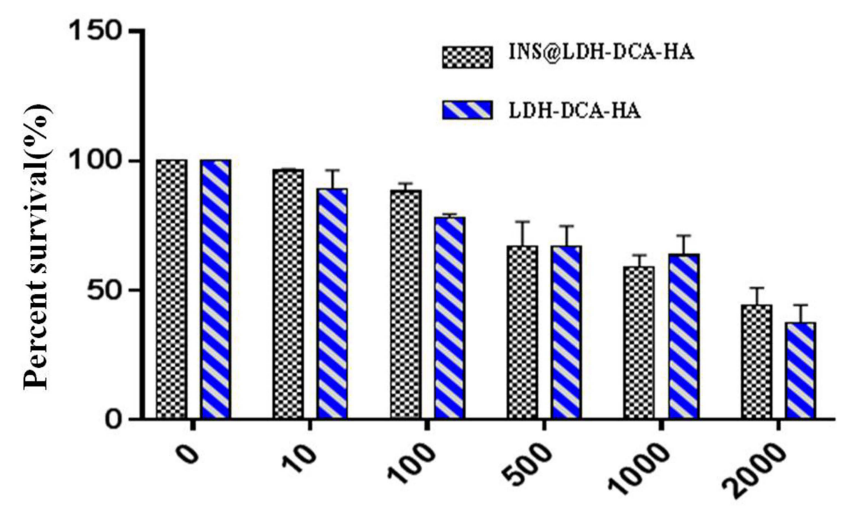

Concentration $(\mu \mathrm{g} / \mathrm{mL})$

Figure 5 Cytotoxicity of LDH-DCA-HA and INS@LDH-DCA-HA nanoparticles.

consumed in the cellular bypass process. After the removal of INS@LDH-DCA-HA, ZO-1 protein levels gradually increased (Figure 8), suggesting that INS@LDH-DCA-HA was able to reversibly open the TJs between cells, which was consistent with the abovementioned outcomes of the TEER analysis.

\section{Hypoglycemic Effect of INS@LDH-DCA- HA}

The blood glucose results showed no hypoglycemic effect in the $\mathrm{NC}$ and oral free insulin groups. Conversely, a significant hypoglycemic effect was observed in the subcutaneous insulin injection group. In the INS@LDH-DCA-HA group, blood glucose significantly decreased over the $8 \mathrm{~h}$ period after oral administration, followed by a slow rise during the subsequent

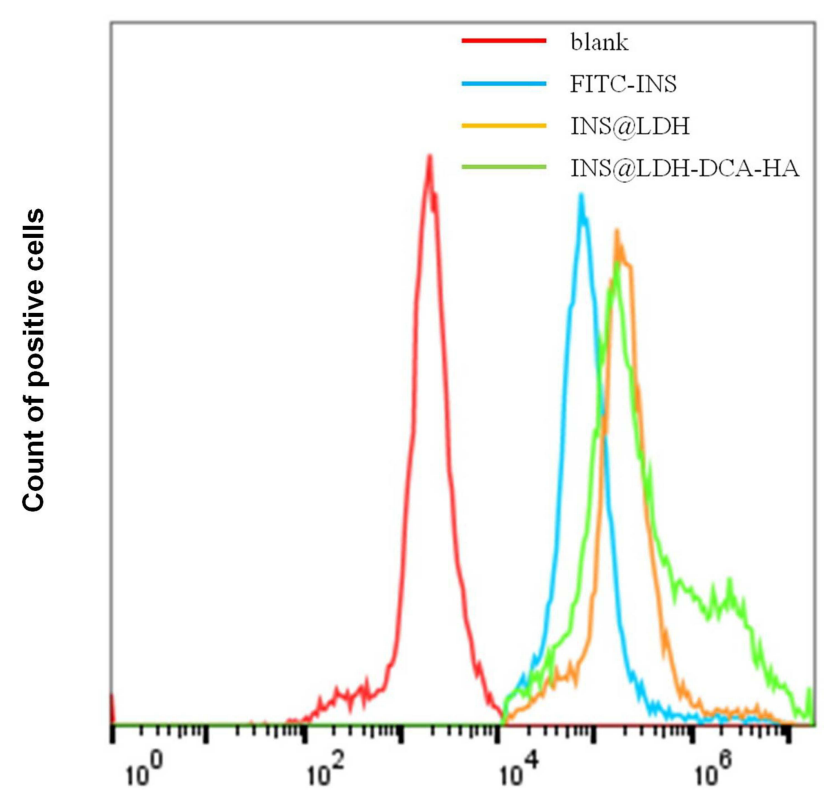

FL1-H:: FL1-H

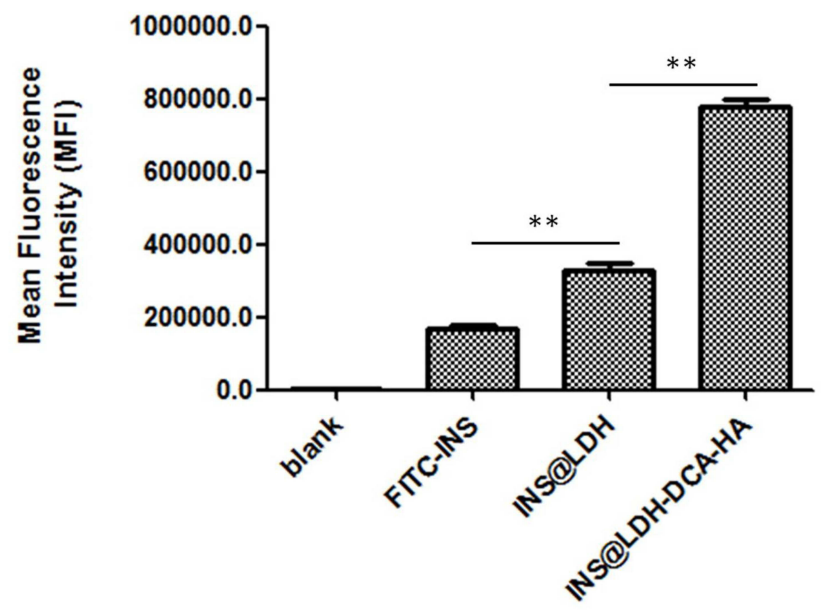

Figure 6 Cell uptake analysis of INS@LDH and INS@LDH-DCA-HA. **P<0.0I.

$4 \mathrm{~h}$ period, suggesting a slow hypoglycemic effect that lasted $12 \mathrm{~h}$ (Figures 9 and $\underline{\mathrm{S} 1}$ ). Additionally, there was a smaller postprandial blood glucose fluctuation range for the oral INS@LDH-DCA-HA group as compared with the subcutaneous insulin injection group, which is more favorable in the treatment of diabetes. ${ }^{15}$

\section{Transport and Absorption of INS@LDH-DCA-HA Nanoparticles in the Small Intestine}

CLSM showed that free FITC-insulin was slightly expressed in the villous epithelial cells of the small intestine, whereas INS@LDH-DCA-HA was extensively 


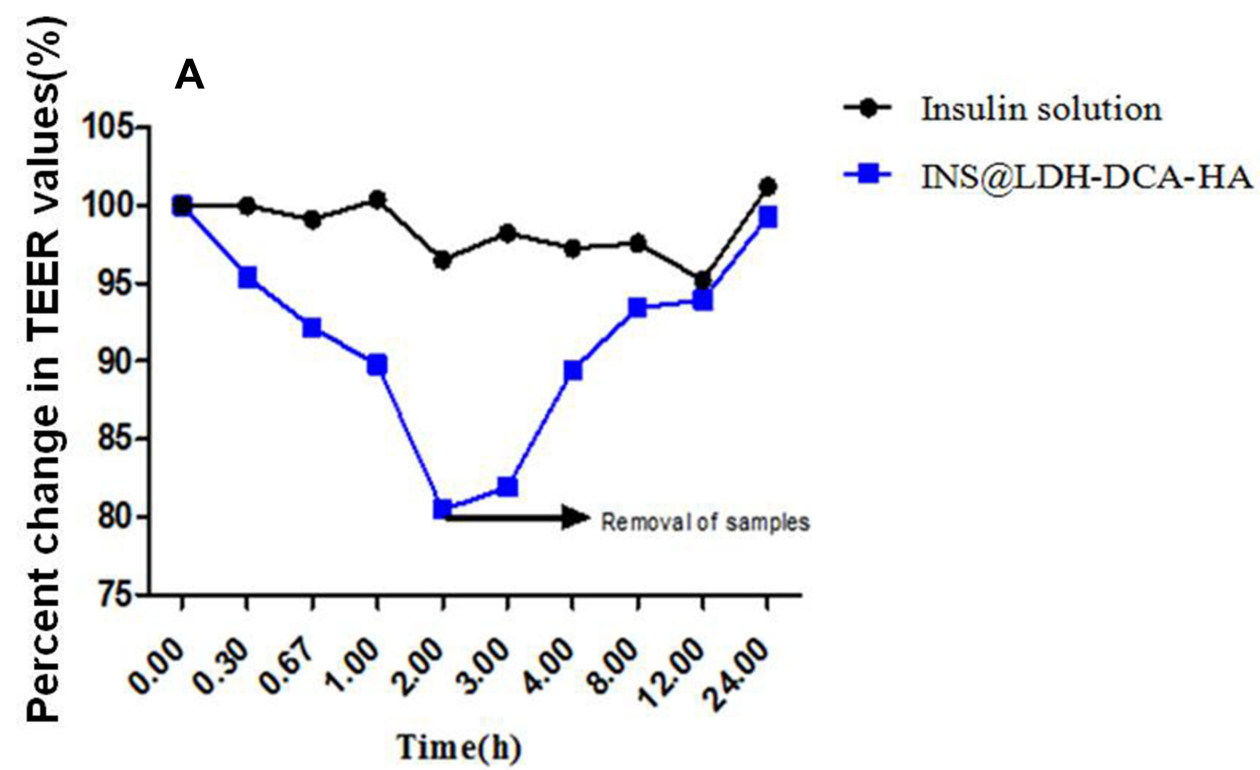

B $\quad \mathbf{E \times \infty}$ Insulin solution

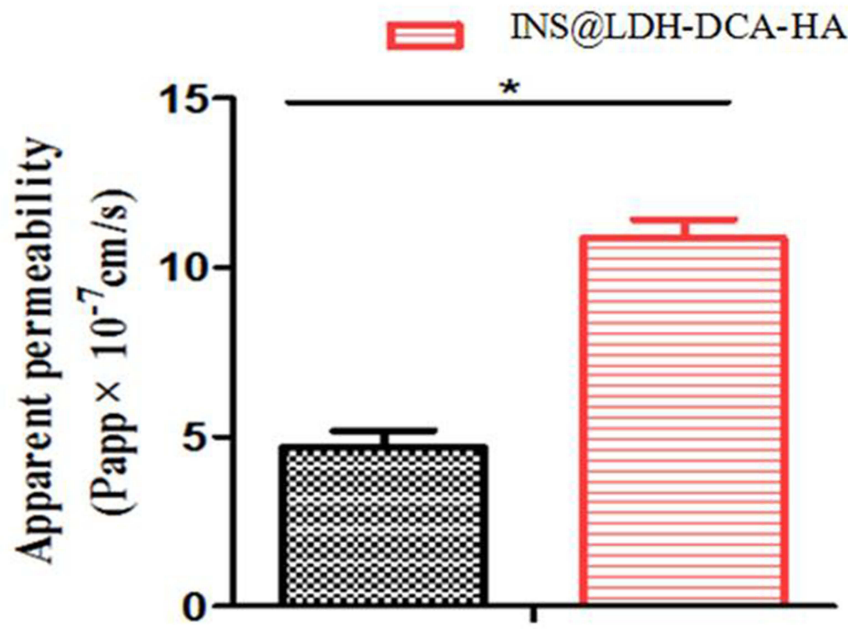

Figure 7 Transepithelial transport of insulin. (A) Effects of insulin solution and INS@LDH-DCA-HA NPs on transepithelial transport of Caco-2 cell monolayer. (B) Apparent permeability coefficient (Papp) of insulin across Caco-2 monolayer with incubation for $2 \mathrm{~h}$. *P $<0.05$.

Before incubation

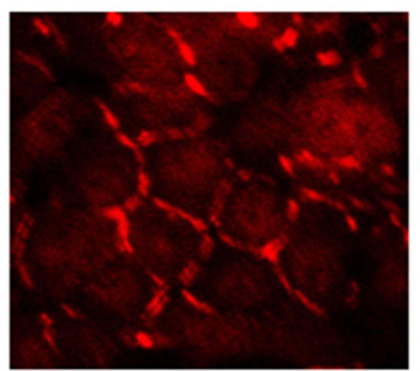

$2 \mathrm{~h}$ after incubation

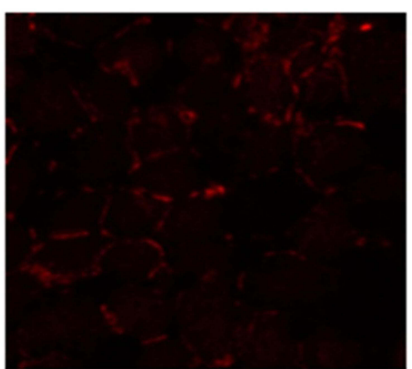

$12 \mathrm{~h}$ after removal of NPs

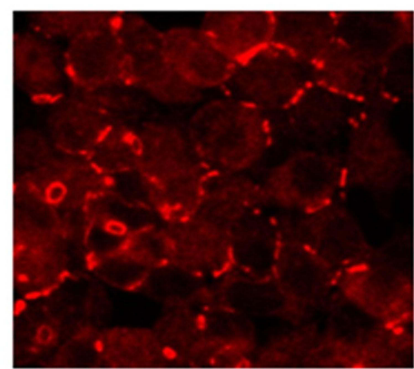

Figure 8 Fluorescence images of Caco-2 monolayer stained for tight junction protein zonula occludens-I (Zo-I) after incubation with INS@LDH-DCA-HA nanoparticles. 


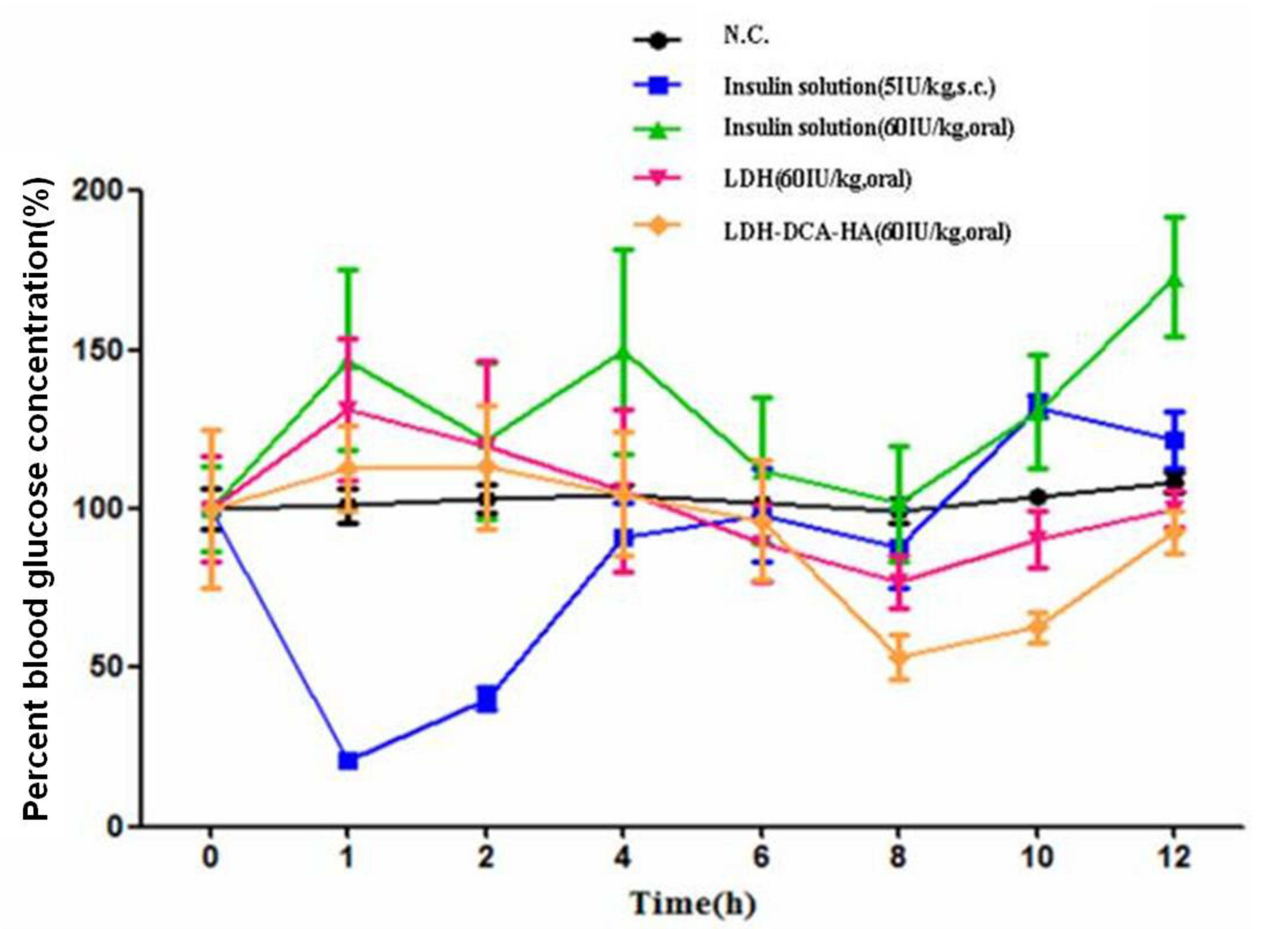

Figure 9 Hypoglycemic effect of insulin delivered by LDH and LDH-DCA-HA via oral drug delivery.

distributed, both on the surface and inside the intestinal villi, suggesting that LDH-DCA-HA nanoparticles effectively permeated the villous epithelial cells of the small intestine (Figure 10A). Moreover, the results revealed that INS@LDH-DCA-HA successfully transported insulin into the cells, compared with the addition of free insulin to the small intestine cells (Figure 10B), further confirming the satisfactory penetration ability of INS@LDH-DCA-HA. Moreover, the expression of SLC10A1 protein was analyzed via IHC in the same part of the small intestine, revealing high protein expression levels in the insulinabsorbing portion (Figure 10C).

The receptor-blocked experiment showed that after oral administration with deoxycholic acid, the fluorescence of FITC-insulin evidently decreased (Figure 10A and D). Therefore, it is likely that DCA-HA-modified LDH nanoparticles effectively delivered insulin to the cell through the cholic acid transporter, promoting the absorption of insulin in the small intestine.

\section{Discussion}

In recent years, LDH has been increasingly applied in the field of biomedicine, and its advantages in drug delivery have been recognized by a growing number of studies. It has been reported that LDH not only improves the delivery of poorly water-soluble drugs but also targets drug delivery in a cell- or tissue-specific manner. This is mediated through its effect on $\mathrm{TJ}$ proteins and the epithelial cell barrier in the process of delivering macromolecules to intracellular action sites. ${ }^{16,17}$ However, due to insufficient surface stability, the original nanoparticles are often unstable in vivo. ${ }^{18,19}$

A previous study showed that the expression modification of LDH improves its efficiency and controls the duration of action of a drug, ${ }^{5}$ which is of major importance for our study with regard to improving insulin absorption. The unique transmembrane transport pathway and targeted transport characteristics of cholic acid render it possible to modify LDH with DCA. In this study, LDH was prepared first and modified with DCA-HA to explore the insulinloading potential of LDH-DCA-HA. Subsequent infrared spectrum, morphological, XPS, and BET multiple analyses as well as TGA confirmed the successful coating of DCAHA in LDH. Moreover, Zhang et al found that a larger LDH particle size ${ }^{20}$ was positively correlated with a longer drug release time. The data in this study showed that the particle size of LDH modified with DCA and HA was significantly larger than that of unmodified LDH. After the addition of insulin to synthesize INS@LDH-DCAHA, XRD analysis confirmed that LDH-DCA-HA successfully loaded insulin. 
A

Insulin solution

INS@LDH-DCA-HA

INS@LDH-DCA-HA (after DCA treated)
Merge
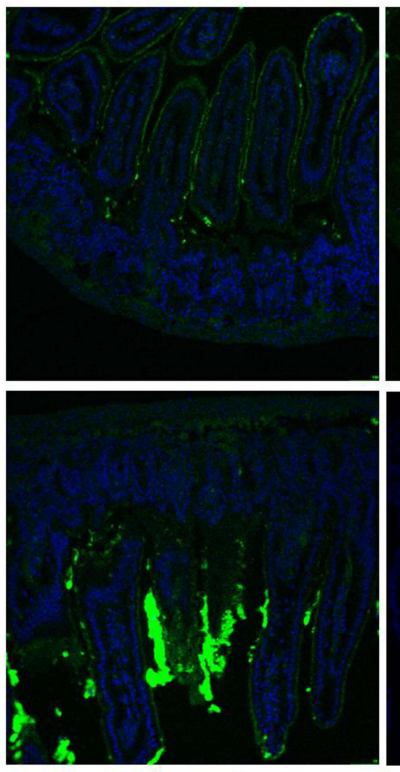

FITC-Insulin
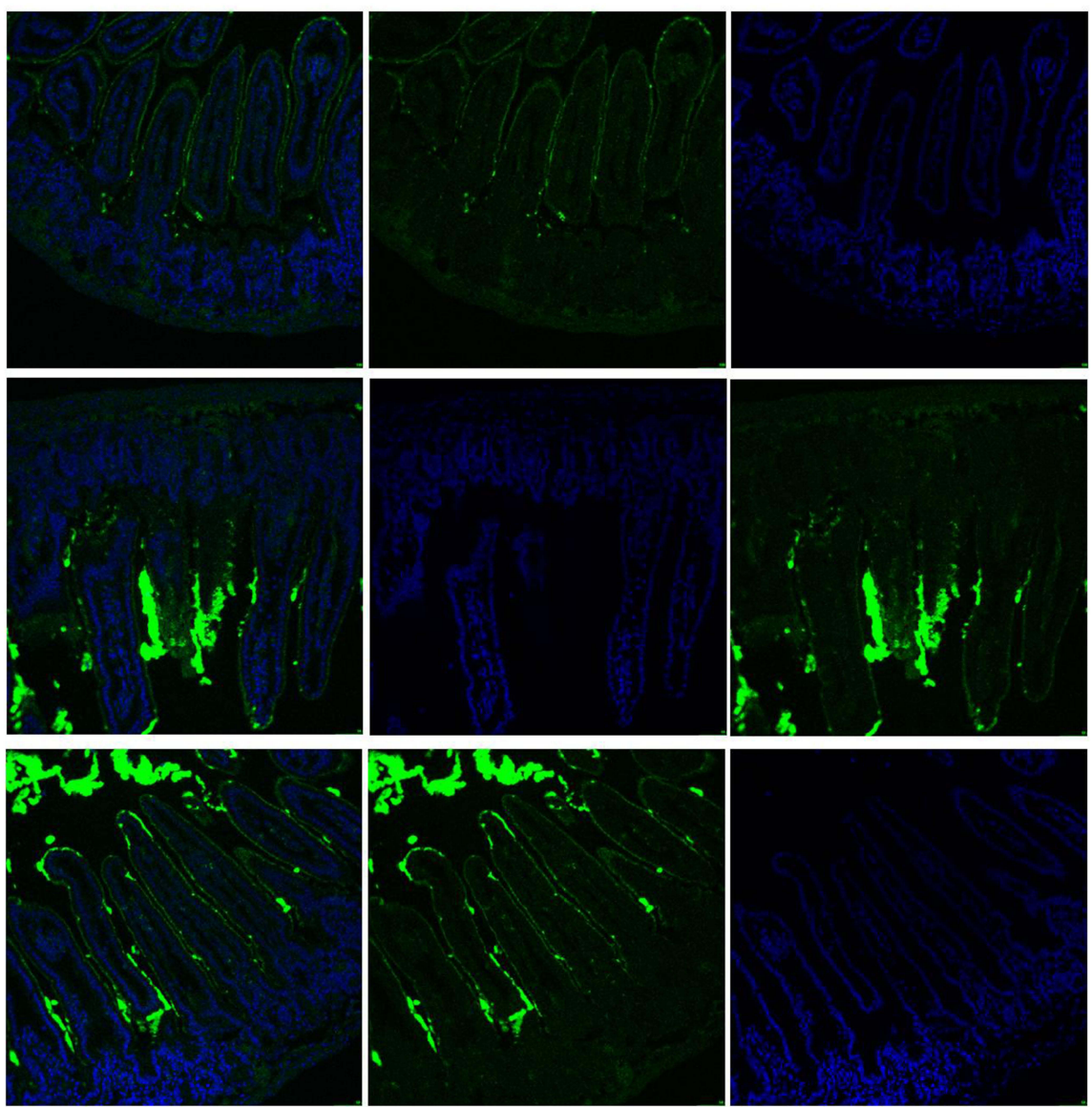

B

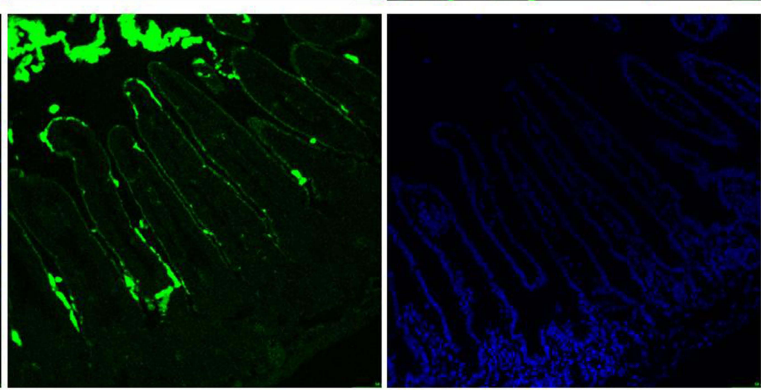

INS@LDH-DCA-HA

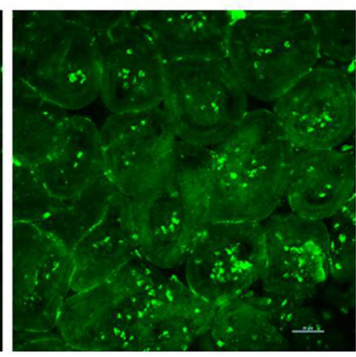

C

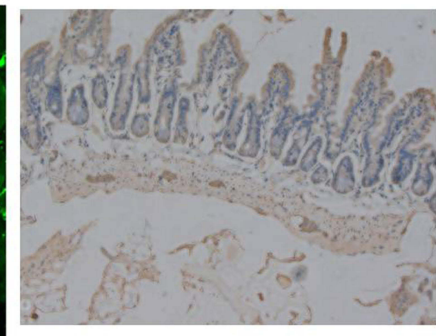

D

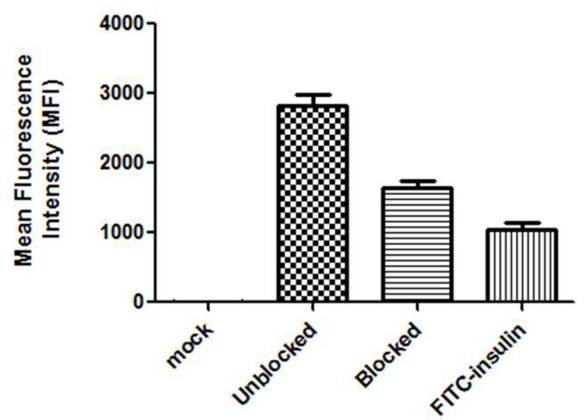

Figure 10 Intestinal sections in vitro. (A) Representative fluorescence-based images of intestinal villi after administration of fluorescently-labeled NPs in TID rats. Insulin was labeled with FITC, and the nucleus was stained with DAPI. (B) CLSM images of intestinal lining cells. (C) Expression of SLCIOAI protein in the small intestine. (D) A statistic of FITC-insulin in the small intestine was carried out by counting pixels of green (signals of FITC) in each picture. 
In this study, the biocompatibility of LDH-DCA-HA and INS@LDH-DCA-HA was analyzed by MTT assay. The results showed that Caco- 2 cell viability was maintained above $60 \%$ when the material concentration was less than $1000 \mu \mathrm{g} / \mathrm{mL}$, indicating that the drug-loaded nanoparticles prepared with LDH as a carrier material exhibited satisfactory biocompatibility with and low cytotoxicity to Caco-2 cells. This is consistent with the results of previous studies confirming the low toxicity of LDH to ovarian cancer cells. ${ }^{21,22}$

Subsequent cell-uptake experiments suggested that LDH-DCA-HA could enhance the uptake of insulin by Caco-2 cells and achieve ideal endocytosis, which was largely attributed to the protective effect of HA on insulin nanoparticles. Additionally, DCA modified LDH, thereby realizing the targeted drug delivery of DCA and enhancing drug uptake by the cells. Hossen et al also noted that targeting ligands on the surface of nanocarriers is important for targeted drug delivery, ${ }^{23}$ which is similar to our findings.

$\mathrm{TJ}$ protein $\mathrm{ZO}-1$ is an indicator protein that maintains the mucosal epithelial mechanical barrier and permeability, which is crucial for intestinal barrier defense ability. Loss of ZO-1 is closely related to a series of disease conditions, including sepsis and hyperglycemia. ${ }^{24,25}$ Studies have shown that drugs can achieve limited bioavailability by transporter-mediated penetration through the mucus barrier without opening TJs. ${ }^{26}$ Another important finding of our study is the ability of INS@LDH-DCA-HA to reversibly open TJs, providing an excellent route for insulin delivery into cells, which may greatly improve insulin absorption, while simultaneously rendering INS@LDH-DCA-HA biosecure.

We found that INS@LDH-DCA-HA successfully delivered insulin into murine small intestinal cells with satisfactory penetration ability, generating a notable hypoglycemic effect. Moreover, the double-layered structure of LDH allows insulin to be slowly released, with the duration of action of INS@LDH-DCA-HA reaching up to 12 h. SLC10A1 is a bile acid co-transporter intact membrane glycoprotein that mediates drug transport in the small intestine. ${ }^{27}$ Herein, we confirmed the presence of a large number of cholic acid transporter proteins at the insulin absorption site via IHC analysis, and a SLC10A1-blocked experiment was carried out to show that INS@LDH-DCAHA could enhance oral insulin delivery efficiency via the cholic acid transporter receptor protein.

\section{Conclusion}

In this study, INS@LDH-DCA-HA was formed with maximum EE and drug LC of $66 \%$ and $33 \%$, respectively. Transmembrane transport of insulin was enhanced by the reversible opening of TJs, increasing the absorption of drugloaded nanoparticles in the small intestine and exerting a steady hypoglycemic effect. To the best of our knowledge, this study is the first to modify LDH with a combination of DCA and HA, in addition to loading with insulin. Nonetheless, the exact utility and mechanisms of INS@LDH-DCA-HA are still unclear and warrant further research.

\section{Acknowledgments}

This work was supported by the National Natural Science Foundation of China [81673360], Major Science and Technology Innovation Projects of Shandong Province [2018CXGC1408] and Science and Technology Projects for people's livelihood of Qingdao [18-6-1-93-nsh]. We thank LetPub (www.letpub.com) for its linguistic assistance during the preparation of this manuscript.

\section{Disclosure}

The authors report no conflicts of interest in this work.

\section{References}

1. Lebovitz HE. Insulin resistance: definition and consequences. Exp Clin Endocrinol Diabetes. 2001;109(Suppl 2):S135-148. doi:10.1055/ s-2001-18576

2. Tee JK, Yip LX, Tan ES, et al. Nanoparticles' interactions with vasculature in diseases. Chem Soc Rev. 2019;48(21):5381-5407. doi: $10.1039 / \mathrm{c} 9 \mathrm{cs} 00309 \mathrm{f}$

3. Xu T, Liu J, Sun L, Zhang R, Xu ZP, Sun Q. Enhancing tumor accumulation and cellular uptake of layered double hydroxide nanoparticles by coating/detaching $\mathrm{pH}$-triggered charge-convertible polymers. ACS Omega. 2021;6(5):3822-3830. doi:10.1021/ acsomega.0c05520

4. Cao F, Wang Y, Ping Q, Liao Z. Zn-Al-NO(3)-layered double hydroxides with intercalated diclofenac for ocular delivery. Int $J$ Pharm. 2011;404(1-2):250-256. doi:10.1016/j.ijpharm.2010.11.013

5. Wei WH, Dong XM, Liu CG. In vitro investigation of self-assembled nanoparticles based on hyaluronic acid-deoxycholic acid conjugates for controlled release doxorubicin: effect of degree of substitution of deoxycholic acid. Int J Mol Sci. 2015;16(4):7195-7209. doi:10.3390/ ijms 16047195

6. Canibano-Hernandez A, Saenz Del Burgo L, Espona-Noguera A, et al. Hyaluronic acid enhances cell survival of encapsulated insulin-producing cells in alginate-based microcapsules. Int J Pharm. 2019;557:192-198. doi:10.1016/j.ijpharm.2018.12.062

7. Zhu J, Jiang G, Hong W, et al. Rapid gelation of oxidized hyaluronic acid and succinyl chitosan for integration with insulin-loaded micelles and epidermal growth factor on diabetic wound healing. Mater Sci Eng C Mater Biol Appl. 2020;117:111273. doi:10.1016/j.msec.2020.111273

8. Han L, Zhao Y, Yin L, et al. Insulin-loaded $\mathrm{pH}$-sensitive hyaluronic acid nanoparticles enhance transcellular delivery. AAPS PharmSciTech. 2012;13(3):836-845. doi:10.1208/s12249-012-9807-2 
9. Tian H, He Z, Sun C, et al. Uniform core-shell nanoparticles with thiolated hyaluronic acid coating to enhance oral delivery of insulin. Adv Healthc Mater. 2018;7(17):e1800285. doi:10.1002/adhm.20 1800285

10. Wagner AM, Gran MP, Peppas NA. Designing the new generation of intelligent biocompatible carriers for protein and peptide delivery. Acta Pharm Sin B. 2018;8(2):147-164. doi:10.1016/j.apsb.20 18.01.013

11. Liu Y, Zhou C, Wei S, et al. Paclitaxel delivered by CD44 receptor-targeting and endosomal $\mathrm{pH}$ sensitive dual functionalized hyaluronic acid micelles for multidrug resistance reversion. Colloids Surf B Biointerfaces. 2018;170:330-340. doi:10.1016/j.colsurfb.20 18.06.024

12. Sung HW, Sonaje K, Liao ZX, Hsu LW, Chuang EY. pH-responsive nanoparticles shelled with chitosan for oral delivery of insulin: from mechanism to therapeutic applications. Acc Chem Res. 2012;45 (4):619-629. doi:10.1021/ar200234q

13. Sugano K, Kansy M, Artursson P, et al. Coexistence of passive and carrier-mediated processes in drug transport. Nat Rev Drug Discov. 2010;9(8):597-614. doi:10.1038/nrd3187

14. Jin X, Luong TL, Reese N, et al. Comparison of MDCK-MDR1 and Caco-2 cell based permeability assays for anti-malarial drug screening and drug investigations. J Pharmacol Toxicol Methods. 2014;70 (2):188-194. doi:10.1016/j.vascn.2014.08.002

15. Maruyama N, Abe M. Targets and therapeutics for glycemic control in diabetes patients on hemodialysis. Contrib Nephrol. 2018;196:37-43. doi:10.1159/000485695

16. Kura AU, Hussein Al Ali SH, Hussein MZ, Fakurazi S, Arulselvan P. Development of a controlled-release anti-parkinsonian nanodelivery system using levodopa as the active agent. Int $J$ Nanomedicine. 2013;8:1103-1110. doi:10.2147/IJN.S39740

17. Saifullah B, Hussein MZ, Hussein-Al-Ali SH, Arulselvan P, Fakurazi S. Sustained release formulation of an anti-tuberculosis drug based on para-amino salicylic acid-zinc layered hydroxide nanocomposite. Chem Cent J. 2013;7(1):72. doi:10.1186/1752$153 \mathrm{X}-7-72$

18. Choi SJ, Choy JH. Layered double hydroxide nanoparticles as target-specific delivery carriers: uptake mechanism and toxicity. Nanomedicine (Lond). 2011;6(5):803-814. doi:10.2217/nnm.11.86
19. Zhou X, Wu HW, Long RM, et al. Oral delivery of insulin with intelligent glucose-responsive switch for blood glucose regulation. J Nanobiotechnol. 2020;18:96. doi:10.1186/s12951-020-00652-Z

20. Zhang XQ, Zeng MG, Li SP, Li XD. Methotrexate intercalated layered double hydroxides with different particle sizes: structural study and controlled release properties. Colloids Surf $B \quad$ Biointerfaces. 2014;117:98-106. doi:10.1016/j.colsurfb.20 14.02 .018

21. Behzadi Nia S, Pooresmaeil M, Namazi H. Carboxymethylcellulose/ layered double hydroxides bio-nanocomposite hydrogel: a controlled amoxicillin nanocarrier for colonic bacterial infections treatment. Int J Biol Macromol. 2020;155:1401-1409. doi:10.1016/j.ijbiomac.20 19.11.115

22. Allou NB, Yadav A, Pal M, Goswamee RL. Biocompatible nanocomposite of carboxymethyl cellulose and functionalized carbon-norfloxacin intercalated layered double hydroxides. Carbohydr Polym. 2018;186:282-289. doi:10.1016/j.carbpol.20 18.01.066

23. Hossen S, Hossain MK, Basher MK, Mia MNH, Rahman MT, Uddin MJ. Smart nanocarrier-based drug delivery systems for cancer therapy and toxicity studies: a review. J Adv Res. 2019;15:1-18. doi:10.1016/j.jare.2018.06.005

24. Assimakopoulos SF, Akinosoglou K, de Lastic AL, Skintzi A, Mouzaki A, Gogos CA. The prognostic value of endotoxemia and intestinal barrier biomarker ZO-1 in bacteremic sepsis. Am J Med Sci. 2020;359(2):100-107. doi:10.1016/j.amjms.2019.10.006

25. Zhang S, An Q, Wang T, Gao S, Zhou G. Autophagy- and MMP-2/ 9-mediated reduction and redistribution of ZO-1 contribute to hyperglycemia-increased blood-brain barrier permeability during early reperfusion in stroke. Neuroscience. 2018;377:126-137. doi:10.1016/j.neuroscience.2018.02.035

26. Han X, Lu Y, Xie J, et al. Zwitterionic micelles efficiently deliver oral insulin without opening tight junctions. Nat Nanotechnol. 2020;15(7):605-614. doi:10.1038/s41565-020-0693-6

27. Stieger B. The role of the sodium-taurocholate cotransporting polypeptide (NTCP) and of the bile salt export pump (BSEP) in physiology and pathophysiology of bile formation. Handb Exp Pharmacol. 2011;(201):205-259. doi:10.1007/978-3-642-14541-4_5
International Journal of Nanomedicine

\section{Publish your work in this journal}

The International Journal of Nanomedicine is an international, peerreviewed journal focusing on the application of nanotechnology in diagnostics, therapeutics, and drug delivery systems throughout the biomedical field. This journal is indexed on PubMed Central, MedLine, CAS, SciSearch ${ }^{\circledR}$, Current Contents ${ }^{\circledR} /$ Clinical Medicine,
Journal Citation Reports/Science Edition, EMBase, Scopus and the Elsevier Bibliographic databases. The manuscript management system is completely online and includes a very quick and fair peer-review system, which is all easy to use. Visit http://www.dovepress.com/ testimonials.php to read real quotes from published authors. 